\title{
Relationship of Venous Clinical Severity Score with Reflux and Leg Vein Diameters Based on Ultrasonography in Women Workers with Risk Factors Patrianef Darwis ${ }^{*}$, I Made Arya Winatha ${ }^{b}$, Aria Kekalih ${ }^{c}$
}

Introduction: In 2010, the American Venous Forum developed a Venous Clinical Severity Score (VCSS) scoring system to assess the severity of Chronic Venous Insufficiency (CVI), where this system was said to be more comprehensive than the CEAP system. However, VCSS validation was still lacking. The purpose of this study was to examine VCSS for reflux and leg vein diameter based on ultrasonography.

Method: This study was a cross-sectional diagnostic test on women workers with standing work positions of 114 people (228 limbs) in Jakarta. VCSS assessment and ultrasound examinations were carried out on all subjects. The relationship between VCSS with reflux and leg vein diameter was analyzed using an odds ratio with a $95 \%$ confidence interval.

Results: From 228 examined limbs, the VCSS score of $0-3$ was $18.4 \%$, and the score of $\geq 4$ was $81.6 \%$. Reflux was found in $21.9 \%$ of the limbs. There was a significant relationship between VCSS and reflux in leg veins. The diameter of the great saphenous vein was between 2.1-12.2 mm, the femoral vein was 7.1-17 mm, the popliteal vein as 3-11.4, and the small saphenous vein was $1.7-7 \mathrm{~mm}$. When VCSS was analyzed for association with venous diameter, a significant relationship was found. VCSS sensitivity compared with reflux based on USG was $78 \%$, specificity was $98.31 \%$, positive predictive value was $92.86 \%$, and the negative predictive value was $93.86 \%$.

Conclusion: From the results of this study, it was concluded that the VCSS score could be used as a method for assessing chronic venous insufficiency. Although VCSS is was to assess the severity of the chronic venous disease, VCSS can also be used for screening because it shows a good relationship with the reflux and venous diameter of the limbs based on ultrasound.

Keywords: VCSS, CVI, vein reflux, leg vein diameter https://doi.org/10.36864/jinasvs.2020.1.004

${ }^{*}$ Correspondence: patrianef@gmail.com

a.D., Vascular and Endovascular Division, Department of Surgery, Cipto Mangunkusumo Hospital - Faculty of Medicine, Universitas Indonesia, Jakarta, Indonesia

${ }^{b}$ M.D., Provinsi Nusa Tenggara Barat Hospital, West Nusa Tenggara, Indonesia

cM.D., M.T.I., Ph.D., Department of Community Medicine, Faculty of Medicine Universitas Indonesia, Jakarta, Indonesia

\section{INTRODUCTION}

Chronic venous insufficiency (CVI) is a health problem that still commonly found in many places. ${ }^{1}$ The prevalence of CVI in adults was reported to be $60 \%$ in developed countries. ${ }^{2}$ However, epidemiological research on this disease has not been done much, including in Indonesia.

The American Venous Forum developed the Venous Clinical Severity Score (VCSS) as an instrument for assessing symptoms in CVI and showed good compatibility when compared with the CEAP classification and abnormalities in ultrasonographic examination results. In Indonesia, this instrument has never been validated. This study aims to compare the use of VCSS in Indonesia with reflux and leg vein diameter based on ultrasound examination results.

\section{METHOD}

This study was a diagnostic test with a crosssectional design to determine the sensitivity and specificity of the assessment of the degree of chronic venous insufficiency with the VCSS scoring method compared to the results of the ultrasound examination. The research sample was female workers in the garment factory of PT TEI Jakarta, who have standing work positions, as many as 114 people (228 limbs). 
We collected the data from medical record database of the Division of Vascular and Endovascular Surgery, Cipto Mangunkusumo Hospital - Faculty of Medicine, Universitas Indonesia in the form of demographic data, VCSS scoring, and ultrasound examination results. The data were processed using SPSS version 20 for Windows $®$. Diagnostic tests were performed to determine sensitivity, specificity, positive predictive values, negative predictive values, and accuracy compared to reflux and diameter based on ultrasound. Reflux was defined as a backflow of more than 0.5 seconds at the great saphenous vein, saphenofemoral junction, small saphenous vein and saphenopopliteal junction, and more than one second
From the data collection, there were 114 research subjects (228 legs) female workers with standing work positions (table 1 ).

VCSS assessment on 228 limbs of 114 subjects obtained a range of scores from 0 to 9 of the total score of 0 to 30 . We grouped into positive and negative groups. A positive group had a VCSS score of $\geq 4$, which means the subject had chronic venous insufficiency disease, whereas a negative group with a VCSS score of 0-3 means the study subjects did not have chronic venous insufficiency disease (table 2 ).

From the results of the ultrasound examination, at least 50 limbs (21.9\%) had reflux in one vein segment, where the reflux location was

Table 1. Characteristics of research subjects.

\begin{tabular}{|c|c|c|c|}
\hline 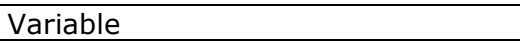 & Total $(n)$ & $(\%)$ & Mean/Median \\
\hline \multicolumn{4}{|l|}{ Age } \\
\hline$\geq 40$ years & 23 & 20,2 & \\
\hline$<40$ years & 91 & 79,8 & \\
\hline \multicolumn{4}{|l|}{ Body mass index $\left(\mathrm{kg} / \mathrm{m}^{2}\right)$} \\
\hline$\geq 25$ & 54 & 47,4 & \\
\hline$<25$ & 60 & 52,6 & \\
\hline \multicolumn{4}{|l|}{ Work experience } \\
\hline$>1$ year & 77 & 67,5 & \\
\hline$\leq 1$ year & 37 & 32,5 & \\
\hline \multicolumn{4}{|l|}{ Give birth } \\
\hline$\geq 2$ & 41 & 36 & \\
\hline$<2$ & 73 & 64 & \\
\hline \multicolumn{4}{|l|}{ Family history of varices } \\
\hline Yes & 19 & 16,7 & \\
\hline No & 95 & 83,3 & \\
\hline \multicolumn{4}{|l|}{$\begin{array}{l}\text { Reflux examination results based on } \\
\text { ultrasound of the leg veins }\end{array}$} \\
\hline Positive & 50 & 21,9 & \\
\hline Negative & 178 & 78,1 & \\
\hline \multicolumn{4}{|l|}{ Great saphenous vein (GSV) } \\
\hline Positive & 44 & 19,3 & \\
\hline Negative & 184 & 80,7 & \\
\hline \multicolumn{4}{|l|}{ Saphenofemoral junction (SFJ) } \\
\hline Positive & 42 & 18,4 & \\
\hline Negative & 186 & 81,6 & \\
\hline \multicolumn{4}{|l|}{ Femoral Vein (FV) } \\
\hline Positive & 0 & 0 & \\
\hline Negative & 228 & 100 & \\
\hline \multicolumn{4}{|l|}{ Popliteal Vein (PV) } \\
\hline Positive & 4 & 1,8 & \\
\hline Negative & 224 & 98,2 & \\
\hline \multicolumn{4}{|l|}{ Saphenopopliteal junction (SPJ) } \\
\hline Positive & 10 & 4,4 & \\
\hline Negative & 218 & 95,6 & \\
\hline \multicolumn{4}{|l|}{ Small saphenous vein (SSV) } \\
\hline Positive & 10 & 4,4 & \\
\hline Negative & 218 & 95,6 & \\
\hline \multicolumn{4}{|l|}{ Diameter } \\
\hline Great saphenous vein (GSV) & & & $3,8(2,1-12,2)$ \\
\hline Femoral Vein (FV) & & & $10,9(7,1-17)$ \\
\hline Popliteal Vein (PV) & & & $6,2(3-11,4)$ \\
\hline Small saphenous vein (SSV) & & & $2,4(1,7-7)$ \\
\hline \multicolumn{4}{|l|}{ VCSS } \\
\hline Positive $(\geq 4)$ & 42 & 18,4 & \\
\hline Mild-moderate (4-7) & 37 & 16,2 & \\
\hline Severe $(\geq 8)$ & 5 & 2,2 & \\
\hline Negative $(0-3)$ & 186 & 81,6 & \\
\hline
\end{tabular}

at the deep vein, namely the femoral and popliteal veins.

\section{RESULTS}

different in each limb. 178 (78.1\%) were found to be normal, either in the absence of reflux or thrombus (table 3). After that, we performed diagnostic test for VCSS to assess reflux with ultrasound as the reference test (table 5), then we analyzed the correlation of location of the reflux in each leg and 
VCSS score (table 6). The analysis result showed a significant correlation between VCSS and reflux in leg veins $(P<0.001$, table 4$)$.

Table 2. VCSS assessment Results.

VCSS Scoring

\begin{tabular}{lcc} 
Result & Total $(\mathrm{n})$ & Percentage $(\%)$ \\
\hline Negative $(0-3)$ & 186 & 81,6 \\
Positive $(\geq 4)$ & 42 & 18,4 \\
\hline
\end{tabular}

Table 3. Ultrasound examination results.

Reflux on ultrasound examination

\begin{tabular}{lll} 
& Frequency $(\mathrm{n})$ & Percentage $(\%)$ \\
\hline Positive & 50 & 21,9 \\
Negative & 178 & 78,1 \\
\hline
\end{tabular}

Accuracy of venous diameter in distinguishing VCSS shown by ROC analysis produced good accuracy, with the area under the curve (AUC) between 79.8 - 91.7\%. GSV had the best diagnostic accuracy with AUC of $91.7 \%$, and subsequently SSV with AUC of $80.3 \%$ (tables 7 and 8 ). Cut-off diameter for FV of $11.4 \mathrm{~mm}$, PV of $6.3 \mathrm{~mm}$, GSV of $5 \mathrm{~mm}$, and SSV of $3.4 \mathrm{~mm}$.

\section{DISCUSSION}

Subjects in this study were female workers who have standing work positions, with a total sample of 114 people (228 limbs). Based on VCSS scoring, it was found that limbs with positive VCSS (score $\geq 4$ ) were 42 limbs (18.4\%). In this study, the prevalence of CVI was smaller than the general prevalence, which around $20-70 \%$. The prevalence of female workers in this study, with risk factors that can increase the incidence of venous diseases such as standing in long hours and has more than one year of service, should be higher than the general population. This can be caused by difficulties in understanding the terminology of CVI itself. Some literature uses the terms and limitations for CVI, varicose veins, and chronic venous disease (CVD). Chronic venous

Table 4. Relationship between VCSS and vein reflux based on ultrasound.

\begin{tabular}{|c|c|c|c|c|c|}
\hline & \multicolumn{2}{|c|}{ VCSS } & \multirow[t]{2}{*}{ Total $(n)$} & \multirow[t]{2}{*}{$\mathrm{p}$} & \multirow[t]{2}{*}{ OR (CI 95\%) } \\
\hline & $\begin{array}{c}\text { Positive } \\
\text { n (\%) }\end{array}$ & $\begin{array}{c}\text { Negative } \\
\mathrm{n}(\%)\end{array}$ & & & \\
\hline $\begin{array}{l}\text { Positive } \\
\text { Negative }\end{array}$ & $\begin{array}{l}39(78) \\
3(1,7)\end{array}$ & $\begin{array}{c}11(22) \\
175(98,3)\end{array}$ & $\begin{array}{c}50 \\
178\end{array}$ & $<0,001^{\mathrm{cs}}$ & $206,82(55,09-776,48)$ \\
\hline
\end{tabular}

Table 5. Diagnostic test results of VCSS for reflux using ultrasound as reference test.

\begin{tabular}{cccccc}
\hline & Sensitivity & Specificity & PPV & NPV & Accuracy \\
& (CI 95\%) & (CI 95\%) & (CI 95\%) & (CI 95\%) & (CI 95\%) \\
\hline \multirow{2}{*}{ VCSS } & 78 & 98,31 & 92,86 & 94,09 & 93,86 \\
& $(64,76-$ & $(95,16-$ & $(80,99-$ & $(89,72-$ & $(89,96-$ \\
& $87,25 \%)$ & $99,43 \%)$ & $97,54 \%)$ & $96,67 \%)$ & $96,31 \%)$ \\
\hline
\end{tabular}

PPV, positive predictive value. NPV, negative predictive value.

Table 6. Relationship between VCSS and reflux locations in leg veins based on ultrasound

\begin{tabular}{|c|c|c|c|c|c|}
\hline & \multicolumn{2}{|c|}{ VCSS } & \multirow[t]{2}{*}{ Total $(n)$} & \multirow[t]{2}{*}{$p$} & \multirow[t]{2}{*}{ OR (CI 95\%) } \\
\hline & $\begin{array}{c}\text { Positive } \\
\text { n (\%) }\end{array}$ & $\begin{array}{c}\text { Negative } \\
\mathrm{n}(\%)\end{array}$ & & & \\
\hline \multicolumn{6}{|l|}{ Reflux GSV } \\
\hline Positive & $38(86,4)$ & $6(13,6)$ & 44 & $<0,001^{\mathrm{cs}}$ & $285(76,70-1059,06)$ \\
\hline Negative & $4(2,2)$ & $180(97,8)$ & 184 & & \\
\hline \multicolumn{6}{|l|}{ Reflux SFJ } \\
\hline Positive & $38(90,5)$ & $4(9,5)$ & 42 & $<0,001^{\mathrm{cs}}$ & $432,25(103,51-1804,99)$ \\
\hline Negative & $4(2,2)$ & $182(97,8)$ & 186 & & \\
\hline \multicolumn{6}{|l|}{ Reflux PV } \\
\hline Positive & $3(75)$ & $1(25)$ & 4 & $0,020^{f}$ & $14,23(1,44-140,44)$ \\
\hline Negative & $39(17,4)$ & $185(82,6)$ & 224 & & \\
\hline \multicolumn{6}{|l|}{ Reflux SPJ } \\
\hline Positive & $9(90)$ & $1(10)$ & 10 & $<0,001^{f}$ & $50,46(6,19-411,58)$ \\
\hline Negative & $33(15,1)$ & $185(84,9)$ & 218 & & \\
\hline \multicolumn{6}{|l|}{ Reflux SSV } \\
\hline Positive & $5(50)$ & $5(50)$ & 10 & $0,021^{f}$ & $4,89(1,35-17,75)$ \\
\hline Negative & 37 (17) & $181(83)$ & 218 & & \\
\hline Total & 42 & 186 & 228 & & \\
\hline
\end{tabular}

Table 7. Relationship between VCSS and Limb Vein Diameter Based on Ultrasound

\begin{tabular}{lccc}
\hline \multicolumn{1}{c}{ Diameter } & Positive & NCSS & Negative \\
& Mean $(\min -\max )$ & Mean $(\min -\max )$ & \\
\hline Femoral vein (FV) & $12,3(8-17)$ & $10,75(7,1-16,5)$ & $<0,001^{\mathrm{mw}}$ \\
Popliteal vein (PV) & $7,45(5,6-11,4)$ & $6,1(3-10,4)$ & $<0,001^{\mathrm{mw}}$ \\
Great saphenous vein (GSV) & $6(3-12,2)$ & $3,6(2,1-8,6)$ & $<0,001^{\mathrm{mw}}$ \\
Small saphenous vein (SPV) & $3,5(2,2-7)$ & $2,35(1,7-6,7)$ & $<0,001^{\mathrm{mw}}$ \\
\hline \multicolumn{4}{c}{ mw Mann-Whitney Test }
\end{tabular}


Table 8. Recommended ROC results and recommended cut-off values

\begin{tabular}{|c|c|c|c|c|}
\hline \multirow[t]{2}{*}{ Variable } & \multirow{2}{*}{$\begin{array}{c}\text { Area under } \\
\text { the curve } \\
\text { (AUC) }\end{array}$} & \multirow[t]{2}{*}{$p$} & \multicolumn{2}{|c|}{ CI $95 \%$} \\
\hline & & & Lower bound & Upper bound \\
\hline VSP diameter & 0,803 & $<0,001$ & 0,741 & 0,866 \\
\hline VF diameter & 0,798 & $<0,001$ & 0,721 & 0,875 \\
\hline VP diameter & 0,809 & $<0,001$ & 0,743 & 0,875 \\
\hline VSM diameter & 0,917 & $<0,001$ & 0,864 & 0,969 \\
\hline
\end{tabular}

disease (CVD) is a chronic venous disorder with a clinical limit of $\mathrm{CO}$ to $\mathrm{C} 6$, while chronic venous insufficiency (CVI) is limited to clinical symptoms that are already rather severe, which is C3 to C6. From this definition, varicose veins (C2) are not a part of chronic venous insufficiency. ${ }^{2-4}$ Nevertheless, some literature also still uses the CEAP C1-C6 clinical classification for the assessment of CVI. In this study, VCSS scoring with cut-off 4 as a positive CVI was in line with the study from Meissner et al. ${ }^{5}$

Among those 228 legs, there were 50 limbs $(21.9 \%)$ with abnormalities on the USG examination in the form of reflux. The prevalence of chronic venous insufficiency in women has been reported between 1$73 \% .^{2}$

VCSS diagnostic test for reflux based on USG found that VCSS sensitivity in assessing chronic venous insufficiency was $78 \%$, specificity $98.31 \%$, and an accuracy value of $93.86 \%$. It can be concluded that the ability of VCSS scoring to detect the presence or absence of chronic venous insufficiency in all subjects was excellent.

There was also a significant relationship between VCSS with leg vein reflux as a whole regardless of the location of reflux $(P<0.001)$. This illustrates that VCSS was a scoring system that can be used to determine whether a person mildly experiences chronic venous insufficiency so that we can use VCSS in daily practical activities, especially for screening. The analysis of each location of the vein (GSV, SFJ, SPJ, PV, and SSV) resulted in a significant relationship ( $P<0.05)$. Ricci et al., compared VCSS with the abnormality found on ultrasound examination in a cohort of 210 patients with hypercoagulable state, showed a strong relationship between VCSS with abnormalities on ultrasound examination (reflux or obstruction). Pasman et al., based on ultrasound screening, obtained reflux in $38.1 \%$ leg veins and $1.5 \%$ obstruction in one of the segments examined. Reflux distribution in each segment showed $18.6 \%$ reflux in the femoral vein, $28.6 \%$ in the great saphenous vein, $9.3 \%$ in the popliteal vein. They also found a relationship between VCSS and abnormalities found on ultrasound (reflux and obstruction). ${ }^{6}$
The relationship between VCSS with the diameter of the leg veins also found a significant relationship $(P<0.05)$. This was consistent with the study from Barros et al. in 2015, which stated there was a relationship between VCSS and the diameter of the great saphenous vein. This shows that the higher the score of VCSS can describe the bigger the diameter of the leg as well. Some researchers found a relationship between venous diameter with reflux images based on ultrasound, where the greater the venous diameter, the higher possibility of reflux. In this study, no test was carried out on these variables.

\section{CONCLUSION}

There was a significant relationship between VCSS with reflux in the leg veins, especially reflux in the great saphenous vein, popliteal vein, small saphenous vein, saphenofemoral junction, and saphenopopliteal junction. There was a relationship between VCSS with the diameter of the femoral vein, the great saphenous vein, the popliteal vein, and the small saphenous vein. VCSS sensitivity was $78 \%$, specificity was $98.31 \%$, positive predictive value was $92.86 \%$, and the negative predictive value was $94.09 \%$. This result shows that the ability of VCSS scoring to detect the presence or absence of chronic venous insufficiency in all subjects was very good.

\section{ACKNOWLEDGMENTS}

The author states the original work, and there is no conflict of interest in doing this research.

\section{ORCID ID OF AUTHORS}

Patrianef Darwis

https://orcid.org/0000-0002-4982-9034

I Made Arya Winatha

https://orcid.org/0000-0002-7407-6206

Aria Kekalih

https://orcid.org/0000-0001-7811-097X

\section{REFERENCES}

1. Raffeto JD, Eberhardt RT. Chronic Venous Disorder: General Considerations. In: Cronenwett JL, Johnston KW (eds) Rutherford's Vascular Surgery. $8^{\text {th }}$ ed. Philadelphia: Elsevier Saunders. 2014

2. Wittens C, Davies AH et al. Management of Chronic Venous Disease. Eur J Vasc Endovasc Surg. 2015; 49:678-737

3. Passman, Marc A. "Validation of Venous Clinical Severity Score (VCSS) with other venous severity assessment tools from the American Venous Forum, National Venous Screening Program". J Vasc Surg 2011;54:2S-9S.

4. Van Bemmelen PS, Bedford G et al. Quantitative Segmental Evaluation of Venous Valvular Reflux with Ultrasonic Duplex Scanning. J vasc Surg 1989;10: 425-31

5. Meissner, Merk $\mathrm{H}$ et al. "Performance characteristics of the Venous Clinical Severity Score". J Vasc Surg 2002:36:889-95.

6. Vasquez, Michael A et al. "Revision of The Venous Clinical Severity Score: Venous Outcomes Consensus Statement: Special Communication of The American Venous Forum Ad Hoc Outcomes Working Group". J Vasc Surg 2010;52:1387-96. 